\title{
Editorial
}

\section{Interventional catheterisation in infants and children}

\author{
CATHERINE BULL \\ From the Hospital for Sick Children, Great Ormond Street
}

In 1975, 15 balloon atrial septostomies were among 503 cardiac catheterisations performed at the Hospital for Sick Children. Last year, 81 of 519 cardiac catheterisations were performed primarily for interventions. These included balloon and blade septostomy; balloon dilatation of pulmonary valves, aortic valves, recoarctations, and pulmonary arteries; myocardial biopsies; and embolisations. The paediatric catheter laboratory, which has been losing diagnostic practice to cross sectional echocardiography, now has a new raison d'être.

The tradition of interventional catheterisation in paediatric cardiology was established in 1966 when Rashkind and Miller introduced balloon atrial septostomy and took the early palliation of transposition of the great arteries out of the hands of the surgeons. ${ }^{1}$ Before that, Brock had pioneered "blind" stargical approaches to the pulmonary ${ }^{2}$ and aortic valves. ${ }^{3}$ As the technology for balloon dilatation of coronary and peripheral arteries flourished, applications in paediatric cardiology were quickly recognised. Balloons have been used to dilate pulmonary valves, ${ }^{4-6}$ pulmonary artery stenoses, ${ }^{7}$ aortic valves, ${ }^{4}$ native coarctations and postoperative recoarctations, ${ }^{8}$ stenotic mitral valves, ${ }^{9}$ pulmonary veins, and caval pathways obstructed after the Mustard procedure. ${ }^{10}$

Radiologists have established the feasibility of therapeutic embolisation, so that virtually any vessel that can be selectively cannulated can be occluded. ${ }^{11}$ The materials available include steel coils, Sterispon fragments, and detachable balloons. Hazards include inadvertent embolisation of normal structures and passage of emboli through arteriovenous shunts. Aortopulmonary collateral arteries seen in pulmonary atresia, coronary fistulas, pulmonary arteriovenous malformations, and surgical shunts have all been successfully occluded, thus avoiding thoracotomy. ${ }^{12}$ With a bigger market in view

Requests for reprints to Dr Catherine Bull, The Hospital for Sick Children, Great Ormond Street, London WC1N 3JH. detachable devices are being developed for the closure of ducts and atrial septal defects. ${ }^{13}$ "Lost" devices are the main hazard with currently available systems, and while failure and complication rates for both techniques run at around $25 \%$, research and development will be confined to a few centres.

Balloon atrial septostomy is widely and safely used in the early palliation of transposition of the great arteries but after about one month of age it produces a inadequate tear in the atrial septum. Blade septectomy, ${ }^{14}$ an extension of the transseptal technique, is used for palliation in older children who have complex conditions with a restriction to right or left atrial outflow or inadequate mixing. Avoidance of even one operation in children who are inevitably going to have multiple procedures, makes the technique worth learning. In a recent cooperative review 41 of 52 patients were improved, one died from lacerated left atrial wall, one had a perforation controlled surgically, and three suffered neurological, presumably embolic, complications. Instruments for myocardial biopsy and the paraphernalia of therapeutic electrophysiological interventions have been borrowed (as yet unminiaturised) from adult cardiology. The main growth area, however, has been in the use of balloons for dilatation.

\section{The appeal of balloon techniques}

Balloon dilatation of the pulmonary valve works. Excellent relief of even severe valvar gradients is the rule. The patients are discharged the next day with no scar on their chests, and money is saved. Data on medium term results suggest that right ventricular pressure stays low or falls further as any infundibular obstruction resolves. ${ }^{5}$ Though surgical operations on the pulmonary valve are performed after early infancy at low risk and with good long term results, the catheter procedure has now virtually replaced operation for the treatment of isolated pulmonary valve stenosis. 
Debate continues about the relative merits of interventional catheterisation and operation for other applications. Operations performed on the stenotic aortic valve in childhood are palliative; all patients need further operation sooner or later. The early results of balloon aortoplasty (for example pressure gradients reduced to one third of predilatation levels) ${ }^{4}$ resemble the results of blind and even open procedures on the aortic valve in early childhood. ${ }^{15}$ It seems likely once some technical problems are solved that this approach will be used more widely. The risk of recoarctation after surgery on aortic coarctation in early infancy is high; the repaired area grows poorly making reoperation necessary. Balloon dilatation of the aortic scar is feasible and a reduction of gradients with return of pulses in the legs is generally, but not always, achieved. ${ }^{8} \mathrm{Bal}-$ loon dilatation of native coarctation has also been described, ${ }^{8}$ but concern about causing aneurysms has prevented many from adopting the technique. About half the stenoses of branches of the pulmonary artery that have been tackled have been successfully dilated. ${ }^{7}$ Closed mitral valvotomy can now be achieved with a balloon catheter introduced transseptally, but because it is more appropriate in rheumatic rather than in congenital mitral stenosis its application in children in the United Kingdom will be limited. ${ }^{9}$

\section{Balloon dilatation of the valves: how it works}

The assumption that congenitally stenosed valves split neatly along fused commissures when a balloon is inflated in the orifice is naive. Firstly, such evidence as exists suggests that the injury is much less precise. A few patients have come to open surgical inspection soon after balloon dilatation, either because of failure to reduce the gradient or because some other component of the heart disease needed repair. For both pulmonary and aortic valves the desired commissural splitting has been seen, but stretching of valve tissue, cusp tearing, and cusp avulsion have also been reported. ${ }^{4}$

Secondly, the underlying pathology of congenital semilunar valve stenosis is quite variable. Valves may be tricuspid or bicuspid with fused commissures amenable to splitting; however, dome shaped membranes and unicuspid or mucoid dysplastic valves occur, particularly in cases presenting very early in life and those with Noonan's syndrome. ${ }^{16}$ Even surgeons have learned not to be too optimistic about reconstruction of such valves and often settle for valve excision in the pulmonary position. Failure to reduce the gradient across such valves has been reported in all large series of balloon pulmonary valvotomy. ${ }^{56}$
Thirdly, some outflow gradients are not solely valvar. In tetralogy of Fallot right ventricular outflow obstruction occurs typically at subvalvar, valvar, and supravalvar levels. Even in isolated pulmonary valve stenosis any associated infundibular gradient will not be reduced and may even be exacerbated by dilatation of the valve. ${ }^{17}$ This infundubular obstruction, which can be severe, often resolves in the months after balloon dilatation, and at later recatheterisation a more favourable result is found.

\section{Balloon dilatation of arteries: how it works}

Relief of obstruction within arterial walls occurs by tearing of the intima and disruption of part or all of the media. This heals over a period of months to a fibrous scar with an intact intima and medial thinning. This has been documented in experimental aortic coarctation and stenosis of branch pulmonary arteries in lambs. ${ }^{1819}$ When only the adventitia holds the vessel together the main concern is the potential for the formation of an aneurysm. Theoretically this is most likely to occur when the dilating force is not concentrically diffused (for example in native coarctation rather than in recoarctation with a circumferential scar), when the obstruction is incompletely relieved (hypertensive stress), and in the systemic rather than the pulmonary circuit. Aneurysms have been seen as early as seven months after dilatation of native coarctation, ${ }^{20}$ but not as yet after relief of recoarctation.

Like stenosed valves, arterial obstructions are variable. If a lesion is very compliant a large diameter balloon will be needed to disrupt the media (for example pulmonary arterial stenoses, for which Lock and his group suggest using a balloon about four times larger than the diameter of the narrowing to be dilated ${ }^{7}$ ). If the lesion if very rigid (for example the peripheral pulmonary stenosis of William's syndrome) a small balloon that will hold a high pressure without bursting is required. Choice of a balloon appropriate to the lesion is important for both success and safety.

\section{Safety}

There are problems; some recorded, some only hearsay. Since many complications are serious and because they are usually technical and predictable, the techniques should be well learned. Currently available balloon catheters are stiff and can perforate the heart or vessels. Moreover, they straighten out as they are inflated so that a long balloon can tear a vessel if, for instance, it is used to dilate round a 
tight corner in a small heart. ${ }^{21}$ Deaths have occurred after pulmonary valvotomy, pulmonary arterial dilatation, ${ }^{7}$ aortic valvotomy, and dilatation of native coarctation. The cardiac output is obstructed for the duration of balloon dilatation of the aortic and pulmonary valves and both syncope and seizures have been seen $^{6}$; arterial blood pressure should be monitored. A few patients have only pinhole patency of a semilunar valve and this can be critically obstructed by even a guidewire. Experienced operators will recognise this situation and not attempt balloon dilatation. Dissection of vessels by guidewires after damage to the intima can be prevented by careful planning of the procedure to avoid recrossing the area of controlled injury. A dissection of intimal peel would be the main concern if dilatation of a stenosed conduit valve were attempted.

Semilunar valve regurgitation seems less of a problem than was expected (this is also true of blind surgical procedures on aortic and pulmonary valves). That well known phrase "mild to moderate aortic regurgitation" describes 15 of 37 of Lababidi et al's patients after aortic valve dilatation. ${ }^{22}$ There is a trade off between using a large diameter balloon for effective relief of the gradient and increasing the probability of valve regurgitation. Thus balloons $30 \%$ larger than the pulmonary annulus diameter are chosen ${ }^{23}$ to give good reduction of the gradient because pulmonary regurgitation is not harmful, whereas balloons that are just smaller than the annulus are used for the aortic valve in an attempt to avoid important valvar regurgitation. An inappropriate balloon may burst inside the lumen of a small vessel; the explosion can produce visible intimal damage. ${ }^{21}$

There are also more mundane but important complications associated with the introduction of large balloons into small arteries. Dilatation of a recoarctation in a $6 \mathrm{~kg}$ child requires the introduction of a $9 \mathrm{~F}$ catheter into the femoral artery. When a percutaneous technique and heparin are used the femoral pulse is usually diminished though not lost; but will such children have a short leg and limp ten years later?

\section{Expectations}

Although we can hope for lower early morbidity and mortality, we cannot realistically expect balloon valvotomy to produce better medium and long term results than blind surgical approaches to aortic and pulmonary valves. We must expect valves to restenose, though the better formed the original valve, the better the relief expected and the longer the intervention will last. For many older children balloon pulmonary valvotomy will be the definitive procedure whereas all aortic valves will probably require re-repair or replacement.

Late aneurysm formation is a major concern in relief of aortic coarctation by both surgical and balloon techniques. An extremely high late incidence of aneurysm is emerging after patch repair of coarctation, ${ }^{24}$ and this makes the early negative findings after balloon dilatation less reassuring. Close follow up with non-invasive imaging of the aortic arch is needed.

\section{Where next?}

The potential for influencing the diameter of congenitally hypoplastic vessels is not clear. Some children with tetralogy of Fallot are not candidates for definitive repair and others with more complex lesions are unsuitable for a Fontan procedure because they have pulmonary arteries that are small from birth and remain hypoplastic. It is probably too optimistic to hope that such patients will be helped by early or repeated dilatation of their proximal pulmonary tree. There is continuing pressure to research applications in areas that are inaccessible to the surgeon or in which surgery is unsatisfactory. Intrapulmonary stenoses and obstruction at the site of insertion of systemic-pulmonary shunts can be reached with catheters, but it is not clear which of these stenoses is amenable to dilatation. Dilatation of circumferential suture lines, including the supravalvar pulmonary stenosis sometimes observed after the switch operation for transposition, may avoid late reoperation. Few acquired systemic venous obstructions (other than intra-atrial obstructions to systemic venous return after the Mustard procedure) have been tackled, though dilatation for congenital pulmonary venous obstruction has been very disappointing. ${ }^{10}$ Finally, a recent abstract describes experimental banding of the pulmonary artery with an absorbable material which can be dilated at a later date. ${ }^{25}$ If it works in practice there will be no shortage of applications for this powerful new surgical technique-the elastic band.

\section{References}

1 Rashkind WJ, Miller WW. Creation of an atrial septal defect without thoracotomy. Palliative approach to transposition of the great arteries. $\mathcal{F} A M A$ 1966;196: 991-4.

2 Brock RC. Pulmonary valvotomy for relief of congenital stenosis. Report of three cases. $\mathrm{Br}$ Med $\mathfrak{F}$ 1948;i:1121-6.

3 Brock RC. Valvotomy for aortic stenosis. Br Heart $\mathcal{f}$ 1954;16:468-73. 
4 Walls JT, Lababidi Z, Curtis JJ, Silver D. Assessment of percutaneous balloon pulmonary and aortic valvuloplasty. F Thorac Cardiovasc Surg 1984;88:352-6.

5 Sullivan ID, Robinson PJ, Macartney FJ, et al. Percutaneous balloon valvuloplasty for pulmonary valve stenosis in infants and children. Br Heart $\mathcal{f}$ 1985;54:435-41.

6 Tynan M, Baker EJ, Rohmer J, et al. Percutaneous balloon pulmonary valvuloplasty. $\mathrm{Br}$ Heart $\mathrm{f}$ 1985;53:520-4.

7 Ring JC, Bass JL, Marvin W, et al. Management of congenital stenosis of a branch pulmonary artery with balloon dilatation angioplasty: report of 52 procedures. F Thorac Cardiovasc Surg 1985;90:35-44.

8 Lababidi ZA, Daskalopoulous DA, Stoeckle H. Transluminal balloon coarctation angioplasty: experience with 27 patients. $A m \mathcal{F}$ Cardiol 1984;54:1288-91.

9 Lock JE, Khalilullah M, Shrivastava S, Bahl V, Keane JF. Percutaneous catheter commissurotomy in rheumatic mitral stenosis. $N$ Engl $f$ Med 1985;313: 1515-8.

10 Lock JE, Bass JL, Castaneda-Zuniga W, Fuhrman BP, Rashkind WJ, Lucas RV. Dilatation angioplasty of congenital or operative narrowings of venous channels. Circulation 1984;70:457-64.

11 Allison DJ. Therapeutic embolisation. Br $\mathcal{f}$ Hosp Med 1978;20:707-15.

12 Fuhrman BP, Bass JL, Castaneda-Zuniga W, Amplatz $\mathrm{K}$, Lock JE. Coil embolisation of congenital thoracic vascular anomalies in infants and children. Circulation 1984;70:285-9.

13 Rashkind WJ. Interventional cardiac catheterisation in congenital heart disease. Int $\mathcal{f}$ Cardiol 1985;7:1-11.

14 Park SG, Neches WH, Mullins C, et al. Blade atrial septostomy: a collaborative study. Circulation 1982;66:258-66.

15 Presbitero P, Somerville J, Revel-Chion R, Ross D. Open aortic valvotomy for congenital aortic stenosis. Br Heart f 1982;47:26-34.

16 Becker AE, Anderson RH. Pathology of congenital heart disease. London: Butterworths, 1981:179.

17 Ben-Shachar G, Cohen MH, Sivakoff MC, Portman MA, Riemenschneider TA, Van Heeckeren DW. Development of infundibular obstruction after percutaneous pulmonary balloon valvuloplasty. $f \mathrm{Am}$ Coll Cardiol 1985;5:754-6.

18 Lock JE, Niemi T, Einzig S, Amplatz K, Burke B, Bass JL. Transvenous angioplasty of experimental branch pulmonary artery stenosis in newborn lambs. Circulation 1981;64:886-93.

19 Lock JE, Niemi T, Burke BA, Einzig S, CastanedaZuniga WR. Transcutaneous angioplasty of experimental aortic coarctation. Circulation 1982;66: $1280-6$

20 Marvin WJ, Mahoney LT, Rose EF. Pathologic sequlae of balloon dilatation angioplasty for unoperated coarctation for the aorta [Abstract]. $\mathcal{F} \mathrm{Am}$ Coll Cardiol 1986;7:117A.

21 Waller BF, Girod DA, Dillon JC. Transverse aortic wall tears in infants after balloon angioplasty for aortic valve stenosis: relation of aortic wall damage to diameter of inflated angioplasty balloon and aortic lumen in seven necropsy cases. $\mathcal{f} \mathrm{Am}$ Coll Cardiol 1984;4:1235-41.

22 Lababidi Z, Walls J, Stoeckle H. Percutaneous balloon aortic valvuloplasty. In: Doyle EF, Engle MA, Gersony WM, Rashkind WJ, Talner NS, eds. Pediatric cardiology. New York: Springer-Verlag, 1986: 334-5.

23 Ring JC, Kulik TJ, Burke BA, Lock JE. Morphologic changes induced by dilatation of the pulmonary valve annulus with overlarge balloons in normal newborn lambs. Am f Cardiol 1985;5:210-4.

24 Ala-Kulju K, Jarvinen A, Maamies T, Mattila S, Merikallio E. Late aneurysms after patclYaortoplasty for coarctation of the aorta in adults. Thorac Cardiovasc Surg 1983;31:301-5.

25 Rocchini AP, Gundry SR, Beekman RH, et al. A reversible pulmonary artery band [Abstract]. $\mathcal{f} \mathrm{Am}$ Coll Cardiol 1986;7:37A. 